\title{
La enseñanza de la redacción desde el punto de vista didáctico
}

\author{
Juan Manuel Alvarez Méndez
}

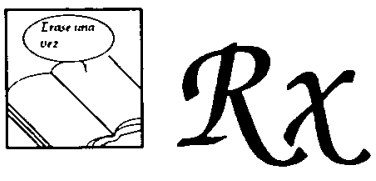

En este articulo se hace una reflexión en profundidad uniendo el proceso de enseñar en general al proceso específico de enseñanza de la redacción, que se configura como tarea interdisciplinar en torno a la escritura como eje integrador para lograr la unidad curricular. Esta reflexión se concreta en 10 prescripciones o sugerencias para la actuación.

\section{INTRODUCCION}

Hay tópicos, temas, contenidos de referencia común y obligada cuando se habla de la enseñanza, de la Lengua o de cualquier otra materia, pero siempre dentro de unos cánones académicamente establecidos de entendimiento esperado entre la comunidad intelectual que se dedica a trabajar sobre los mismos asuntos hasta tal punto que los no iniciados quedan al margen del discurso o elaboran uno propio caracterizado, se dice, por la falta de propiedad y de precisión y de rigor, normalmente científico. Se han creado "comunidades incomunicadas" de expertos que dificultan extremadamente el entendimiento interáreas de conocimiento y lo que es más grave, lo convierten en Bien privilegiado al que sólo acceden unos pocos. Cuando los padres hablan de la escuela en general o de los problemas que tienen sus hijos en la escuela lo hacen con palabras y modos distintos de expresión a como los que utilizan los profesores y a los que utiliza la Administración y a los que utilizan los empleadores. Siendo el referente común -la Escuela - parece que hablan lenguas distintas, unos amparados por el lenguaje «técnico», otros se escudan en el lenguaje de la «expertez», otros hacen uso de la lengua que recoge el sentido común. Lo normal es que, dado que además los intereses son distintos, cada parte no entiende a la otra. $Y$ cada una se considera valedora del bien decir.

Entiendo, en cambio, que hablar desde el punto de vista didáctico supone saltarse tan estrechos márgenes, abriéndose a una necesaria tarea interdisciplinar, e implica clara y definitoriamente dos dimensiones insoslayables e irrenunciables que definen y justifican el enfoque didáctico, por 
más que con ellos pueda correrse el riesgo de complicar los planteamientos de partida.

Por una parte, me refiero a la intencionalidad formativa que conllevan los procesos de enseñanza y de aprendizaje. No se trata (sólo) de instruir o de entrenar en unas destrezas determinadas ni de transmitir información o contenidos hechos materia de estudio, como valores cuyo fin son ellos mismos, de consumo estrictamente académico. A este entendimiento mecanicista responde una tendencia perdurable a reducir la enseñanza y el aprendizaje de la Redacción a un entrenamiento rutinario y con valor conformado por el rendimiento escolar, que no rendimiento en y para la comunicación y desarrollo del pensamiento. Por eso es tan frecuente hablar más de habilidades y destrezas que de capacidades, de pensamiento, de imaginación, de creatividad, de fluidez de ideas, de intereses y de objetivos de quien debe escribir. Se acostumbra a hablar más de enseñanza que de aprendizaje y de comprensión. Más de dominios morfosintácticos - metalengua-, que de sentido y de significado y de entendimiento. Más de tipos de redacción y de pasos o reglas a seguir que de claridad de ideas, de estructuración del pensamiento, de ajuste entre lo que se quiere comunicar y lo realmente recogido en el texto. Más del envoltorio que de las ideas que contiene. Más de lo que es empíricamente verificable y comprobable que de la significación educativa y formativa de lo empírico. Más del producto o resultado final - lo escrito- objeto de control/calificación que del escribir, que es proceso creador y forma activa del pensamiento.

Desde el punto de vista didáctico necesitamos entender la redacción como medio activo de pensamiento y de aprendizaje, un modo de descubrir lo que uno piensa y cómo lo piensa. Se trata más bien de formas a través de las cuales el alumno puede desarrollar sus propias capacidades y lograr la autonomía intelectual que le permitan acceder a las fuentes de los saberes histórica y socialmente establecidos y abrir caminos hacia otros nuevos.

Por otra parte, es propio del enfoque didáctico la pretensión de comprender y de explicar los fenómenos relacionados con la enseñanza y el aprendizaje desde concepciones $y$ análisis globales e integradores que rehuyan reducir los asuntos de aula a cuestiones psicológicas y de desarrollo o de tratamiento del contenido idiomático siguiendo los presupuestos de la tecnología educativa (programaciones exhaustivas y pruebas técnicas de evaluación, normalmente de elección múltiple, que aseguren una pretendida objetividad, aunque en el intento se sacrifique el valor del pensamiento expresado). Por esta vía, tendente a resolver las cuestiones educativas como cuestiones técnicas, corremos el riesgo de llegar a soluciones parciales porque los puntos de referencia de partida marcan ya detalladamente el camino por recorrer sin haberlo andado, anticipando dificultades supuestas, olvidando el contexto real del aula y la historia y la procedencia de los sujetos que la habitan y las formas peculiares que caracterizan sus modos de expresarse, planificando pasos que sólo se justifican desde necesidades instructivas, pero no las reales que encuentran los alumnos y el profesor cuando escriben. Estas sólo aparecen cuando el alumno se enfrenta por primera vez con el reto que supone la hoja en blanco y tiene que llenarla de algo que él no siente (Vygotski, 1982). Pero no hacerlo conlleva su propio riesgo académico, del que es consciente. Nace así la paradoja de que el alumno 
rellena unos folios de algo que no dice, pero que satisface las exigencias impuestas o acordadas para el decir académico.

Desde el punto de vista didáctico trato de buscar el equilibrio, que brindan ciertas formas de concebir el curriculum como un proceso único y común, problemático y conflictivo y en el que se pone en juego una serie de valores plurales que conviene explicitar y tomar conciencia de ellos si no queremos desfigurar y desvirtuar el análisis en su conjunto, que es tanto como renunciar a comprenderlo.

Los tópicos, temas y puntos de referencia comunes deben ser vistos desde perspectivas interdisciplinares e integradoras globales, por reducidas o especificadas que estén en los estrechos márgenes del programa -entiéndase Redacción, por ejemplo-, porque corremos el riesgo de acentuar la desintegración del conocimiento, ya tan parcelado de por sí en currículos multidisciplinares, que son constructos sociales, y ahondar más aún la incomunicación entre los especialistas que se dedican a áreas de especialización que crean sus propias vías de entendimiento, con sus lenguajes específicamente especializados. En esta distribución fragmentaria del saber la Redacción queda separada del aprendizaje: se aprende a escribir pero no se aprende con la escritura. Se aprende a escribir, pero no a escribir para aprender. Escribe el alumno para demostrar que sabe, que es tanto como escribir para ser evaluado/calificado, pero no escribe para comunicar-se. Si acaso, rinde cuenta de lo aprendido por medio de la lengua escrita. Subyace aquí una forma de entender el conocimiento y el aprendizaje, a la cual se ajusta una forma de enseñar, como actividades acumulativas, de suma y de acopio, usualmente identificada con la actividad de tomar apuntes, donde se da implícito o se presupone el aprendizaje. Pero cada una de estas actividades se ejercen en tiempos y espacios de dedicación distintos y aislados, con la esperanza de un aprendizaje para después, que les dará unidad.

Pienso, en contra de esta forma de concebir la enseñanza y el aprendizaje de la lengua escrita, que ella misma es aprendizaje y vehículo para aprendizajes nuevos. En este sentido y de acuerdo con Edward M. White, "ante un curriculum dividido y parcializado, la escritura emerge como una fuerza unificadora e integradora" (1989, pág. 62).

Desde la intencionalidad formativa y desde el análisis global e integrador podremos acercarnos más directamente a la comprensión de los fenómenos que suceden en el aula. De otro modo, corremos el riesgo de desfigurar el escenario habitual, pero no real, en el que se dan los procesos de enseñanza y de aprendizaje y hablar de ellos tan asépticamente que el discurso se vuelve sobre sí mismo en ejercicio de metáfora vacía de contenido créble y veraz. La aplicación descontextualizada de tecnologías curriculares tan al uso no fue ajena a este ir dejando en manos de otros lo que debe ser trabajo y responsabilidad de quienes llevan adelante la enseñanza día a día en las aulas. Recuperar la dignidad y la autonomía del quehacer didáctico es un reto al que no podemos renunciar quienes nos dedicamos de lleno a las tareas de enseñar unos, a las de aprender otros.

\section{EN BUSCA DE LA UNIDAD CURRICULAR A TRAVES DE LA LENGUA}

La necesidad de enseñar la lengua escrita como parte del proceso educativo y como necesidad social compartida es algo que nadie discute hoy 


\section{4}

con seriedad. Como forma fundamental de comunicación reconocida constituye una parte sustantiva del vivir en comunidad en el que nos desenvolvemos, que es vivir en relación.

La lengua escrita, por ceñirnos al tema que aquí nos convoca, es un saber extraordinariamente polivalente y como tal presenta características que lo hacen un medio fundamental para el desarrollo de las capacidades intelectuales del sujeto que aprende en el período escolar asi como para la adquisición, creación y co-participación de nuevos saberes. La lengua escrita trasciende desde esta perspectiva los márgenes artificialmente impuestos por el reparto disciplinar del curriculum y se convierte en parte y medio de aprendizaje, es aprendizaje (el alumno que no aprende a escribir simplemente copia o repite, ejercicios de caligrafía sin más), a la vez que medio elemental de comunicación.

No se puede perder de vista esta doble dimensión que cóntemplamos désde las consideraciones iniciales de nuestra exposición en el contexto escolar -aprendizaje y comunicación - si lo que realmente se pretende es hacer de la enseñanza y del aprendizaje de la Lengua una actividad a la que merece la pena dedicarse pensando en la formación integral del alumno. De lo contrario, no saldremos nunca de la enseñanza centrada en ejercicios de rutina y de memoria que suelen tener en la Gramática el eje vertebrador de explicación teórica y en los ejercicios de análisis morfosintáctico la práctica; pero como contenido estático que paraliza el aprendizaje de una de las partes más dinámicas de la Lengua. El aprendizaje, en esta parcela de conocimiento, está llamado a ser eminentemente activo, lo que equivale a decir que la participación del alumno en el proceso didáctico viene a ser condición imprescindible para la comprensión porque el alumno participa de y con un bagaje idiomático que es experiencia social de intercomunicación y que por tanto, ya conoce.

En diversos contextos culturales y educativos se proclama, además, la necesidad de medidas didácticas urgentes que corrijan los pobres resultados que manifiestan los alumnos en los distintos niveles y grados educativos, incluyendo la Universidad, a la que los alumnos acceden con un rendimiento de las artes básicas de la lengua, es decir, leer, hablar y escribir, igualmente pobres y que afectan al rendimiento escolar.

El problema no es nuevo - ya en 1912 Rodolfo Lenz y Américo Castro en 1922 llamaban la atención sobre la imperiosa necesidad de atender estos dominios idiomáticos fundamentales - ni es, como decía, un problema que se plantee sólo en el contexto lingüístico del español. Pero actualmente hay factores que ayudan a evidenciar esta situación preocupante y que obligan a una toma de conciencia de un asunto que hasta ahora sólo (pre)ocupaba a los maestros que tenían que ver directamente con la enseñanza de la lectura y de la escritura en los primeros años de escuela.

Entre los factores que ayudan a esta nueva situación cuentan, entre otros, el hecho de que existe una mayor demanda y oferta de educación y un aumento considerable de la población escolar por una parte, lo que crea necesidad de medidas que vengan a remediar situaciones desfavorables que los alumnos arrastran desde sus origenes socioculturales y que tienen como punto común de referencia formal el inicio de la escolaridad; y por otra, los conocimientos que aportan los estudios lingǘsticos, sicológicos, sociológicos y curriculares que han venido abriendo horizontes esclarecedores, 
no sólo porque arrojan luz sobre distintos aspectos relacionados con el aprendizaje de la lengua, sino también porque cada día podemos ir comprendiendo que sólo desde planteamientos y enfoques interdisciplinares podremos arribar al buen puerto que es en definitiva el conocimiento y dominio de los recursos expresivos del idioma. De otro modo naufragaremos en el intento de remediar cada uno por nuestra parte la parcela de conocimiento con la que cada uno trabaja, olvidando que tratamos con niveles educativos en los que la educación debe ser global e integral. En ellos, la Lengua es vehículo de todos los aprendizajes y medio de integración en la unidad de conocimientos de un curriculum disperso.

Hay además razones de interés estrictamente académico que afectan a los alumnos dado el peso que van adquiriendo las pruebas de selectividad para el acceso a la Universidad en las que la expresión escrita cobra valores decisivos para la elección de carrera.

En la historia escolar reciente podemos encontrar algunos ejemplos perjudiciales derivados de la parcialización abusiva del conocimiento y del área de la Lengua en particular, la cual está necesariamente presente en todo el curriculum escolar por más que no figure como materia de permanente presencia interáreas. Y esto, de hecho, en una práctica docente que tiende cada día más a la superespecialización, la convierte en un terreno de nadie siendo que la expresión idiomática se sale del marco disciplinar asignado a la etiqueta «Lengua». Así: "que el alumno aprenda a leer y a expresarse adecuadamente al hablar y al escribir» fue siempre un objetivo y un dominio considerado incuestionablemente propio del área de Lengua. No obstante la realidad es que tales aprendizajes sobrepasan ampliamente los estrechos y ficticios márgenes de una disciplina que, siendo producto social e histórico de la división del conocimiento (Goodson, 1987), hoy han adquirido naturaleza y patente de exclusividad, en un doble y paradójico sentido: tanto para reivindicar como propia del área de Lengua la intervención en el aula por parte de unos, como para echarle todas las culpas a los profesores de Lengua de la mala preparación con la que los alumnos llegan a las demás materias de estudio por parte de otros.

En este doble y reducido juego es fácil hallar culpables y es fácil igualmente salir con las manos limpias aunque no se trate con ello de dar solución a un problema que cada vez afecta a más gente, fuera incluso del ámbito estrictamente escolar. Porque la salida, no muy airosa, suele pasar por aceptar como inevitable entre los docentes, hasta el convencimiento y la conveniencia, que los alumnos realmente han perdido el interés por aprender, estimulados por otros medios de comunicación más accesibles y menos laboriosos que los trabajos que exige la escuela y que les permiten vivir en la sociedad actual sin necesidad de escribir una línea. Porque los modelos de cultura ya no son los escritores ni los literatos-que en un tiempo fueron referencia obligada para definir la norma de la lengua escrita--, sino los modelos que proyectan los medios de comunicación social: TV y radio principalmente, pero también cine y prensa, que se sienten como más próximos y más directos (el teléfono, incluso, sustituye en muchos casos el necesario intercambio escrito de antaño).

Ante esta situación, necesitamos recoger velas y analizar la oferta educativa desde dentro para comprender las distancias que median entre ésta y las necesidades reales para las cuales supuestamente la escuela prepara a los 
alumnos. Como ya anuncia el título del trabajo, mi propósito aquí es analizar la enseñanza de la redacción desde el punto de vista didáctico, es decir, en cuanto que es elemento sustantivo de la formación del alumno. Para centrar el tema, haré referencia a la enseñanza de la Lengua como campo de conocimiento en el que aquélla debe tener sentido desde el punto de vista escolar y del análisis del sentido que adquiere dentro del proceso de escolarización.

\section{LA ENSEÑANZA DE LA LENGUA}

El aprendizaje de la lengua es un proceso continuo que no cesa, que está ligado a la experiencia vital y total del sujeto. Paradójicamente sólo los programas escolares dividen y ponen recortes artificiales a este aprendizaje global y permanente. Tal vez en este hecho reside la razón que justifica la permanencia y la constancia de la Lengua como materia de estudio en los programas escolares.

De todos modos, esta presencia continuada a lo largo de toda la escolarización no se ve reflejada en unos resultados que satisfagan a los distintos sujetos implicados en este proceso. Hay varios factores que se pueden señalar como indicadores del desajuste que se aprecia entre la importancia y el tiempo académico que formalmente se concede a la enseñanza de la lengua y los resultados a todas luces insuficientes -alto porcentaje de suspensos y utilización bastante rudimentaria en el dominio idiomático de muchos de los que aprueban- que parecen ser compartidos por una gran mayoría de personas relacionadas con la educación. Pero achacar todos los males del bajo rendimiento a los procesos de enseñanza y de aprendizaje que se dan en el aula, a los profesores porque no aciertan en los objetivos ni en las formas, a los alumnos porque no responden a las demandas y expectativas exigidas en la relación que se establece entre las partes, es reducir el problema a niveles que lo vuelven insignificante.

Pienso que para comprender la enseñanza de la lengua necesitamos enmarcarla en el ámbito más amplio de lo que es en sí mismo el proceso de escolarización en el que la situación que se da en el área de Lengua puede verse más como una muestra de las paradojas que reproducen el discurso del ser y del deber ser de la educación que como problema aislado que sólo atañe al aprendizaje lingüístico. Porque la situación cabe plantearla en otras áreas y formas de conocimiento, bien sean las matemáticas, las ciencias, las artes o el segundo idioma. Todo lo cual, y dado que existen problemas comunes que se reproducen más allá de los límites de cada especialidad, da pie para cuestionar las funciones reales que hoy desempeña la escuela en nuestra sociedad y necesitamos plantearnos los objetivos reales, que no las declaraciones románticas cargadas de promesas redentoras, a que sirve, como digo, el proceso de escolarización. Porque las insuficiencias, digamos, y los obstáculos que hay que vencer son de sobra conocidos. Como también son conocidos los esfuerzos de tantos docentes que se dedican a buscar soluciones a situaciones y problemas que los trascienden. Pero las macroestructuras de Poder (Político y Económico, principalmente) que envuelven este proceso no siempre van a la par con las necesidades sentidas por quienes viven la escuela desde dentro. 
No se puede olvidar este contexto social más amplio si no queremos llegar a interpretaciones que no se corresponden con la realidad inventada que es la Escuela. Aquí el medio es el mensaje, en la célebre expresión de McLuhan. Porque, ciñendo el análisis al área de Lengua, se puede reconocer que la Lengua es comunicación, pero no en la escuela. La Lengua es creación, pero no en la escuela. La Lengua es medio de expresión, pero no en la escuela. Decir entonces que la Lengua es comunicación-expresión no deja de ser en el contexto escolar una parodia o representación de lo que es la comunicación en contextos naturales reales. De ahí que el alumno llega a «comunicarse» en el aula de un modo totalmente disfuncional respecto a la forma habitual de comunicación que conoce en su medio sociocultural (Rockwell, 1982).

La Lengua se entiende y se explica como medio de comunicación y de expresión en la escuela, y se vive como comunicación fuera de ella. Así, encontramos niños que guardan silencio ejemplar durante el horario escolar que rompen en comunicación, no necesaria ni exclusivamente verbal, fuera del mismo. Porque el niño es, ante todo, expresión, comunicación, sea lingüística o gestual o lúdica, aspecto este último permanentemente postergado por el rigor y la seriedad de la estructura disciplinar del programa. En la escuela, la Lengua es una materia del programa que hay que pasar. Fuera de ella, es un medio por el cual los sujetos interactúan, se entienden. Pero dentro de las reglas del juego global que permite la comunicación y la conversación como concreción cotidiana del intercambio lingüistico en la situación conversacional. Para analizarla, es necesario tener presentes las otras acciones de la situación social (cf. Van Dijk, 1983) y en el caso de la enseñanza, la situación escolar. La situación social/escolar queda marcada/mediatizada por el significado latente que se establece entre las partes y el reconocimiento de la función de cada una de ellas, que en la enseñanza es desigual. Entender la Lengua como comunicación e intercambio no deja, pues, de ser una representación de tal propósito.

En primer lugar, porque el espacio es artificial y los contenidos lingüísticos escolares llevan, si acaso, a modos de expresión artificiales para satisfacer la intencionalidad de la tarea realizada. La situación social es forzada. En ella del contenido de lo idiomático queda mediatizado por los valores académicos de la «materia» Lengua.

En segundo lugar, porque además lo que se presenta como natural y propio de la experiencia existencial del sujeto deja tales propiedades para convertirse en materia de enseñanza para unos, en materia de estudios para otros, y en materia de exámenes y controles -ahí está la clave del desaguisado que rompe cualquier pretensión de espontaneidad y de creatividad- para los más. Lo que esencialmente es intercambio, expresión, coparticipación, intencionalidad, interacción social, comunicación en fin, se vuelve en un objeto neutro que no tiene más referentes que él mismo.

Porque, en tercer lugar, los mensajes de tal comunicación son de sobra conocidos para unos - los profesores repiten año tras año los mismos contenidos, los mismos manuales, los mismos mensajes-, sospechados para otros - ya vienen dados en los programas y en los libros de texto-, reconociendo cada parte que los destinatarios de los mensajes que se dan en tal proceso comunicativo son ellos mismos, profesor y alumno, pero en el contexto cerrado del aula. Así, por más apariencias de naturalidad y de ori- 
ginalidad que un alumno quiera dar al escrito cuando redacta, conoce y es consciente de quién será el lector, quién el destinatario, que a la postre será también quien juzgue sobre indices académicos establecidos, el supuesto valor literario de su trabajo. La redacción se convierte entonces en un discurso cerrado que responde a una consigna, a un mandato, a una solicitud. Pero con las cartas marcadas. Se le indica al alumno lo que debe hacer, sabiendo el alumno cómo lo debe hacer no sólo por la forma, sino porque conoce el destinatario y las consecuencias que siguen siempre atendiendo a unos presupuestos implícitos de evaluación que condicionan la propia creación. El alumno buscará con empeño la excelencia lingüistica de que habla P. Bourdieu (1985) caracterizada por la distinción y la corrección, que coincide en definitiva con la excelencia escolar que asegura el éxito escolar (Perrenoud, 1984).

Evidentemente se produce una paradoja propia de la situación instructiva: todo escrito dice algo, todo escrito comunica, en lo que manifiesta y en lo que calla. Pero en el contexto escolar, como señalaba más arriba, dice lo que ya se sabe y se espera que diga. Es un decir vacío, sin ánimo real de comunicar. Si acaso, de repetir (el profesor y el alumno). Pero no de decir fuera de lo previsto (programación). Porque la Lengua en la clase suele entenderse casi exclusivamente como intercambio, medio de dar y obtener información pactada, a través de la cual se producen los procesos de enseñanza y de aprendizaje, pero entendidos no como interacción o intercambio directo, sino como transmisión unidireccional que se da en espacios y sobre todo en tiempos distintos en los que se da la información y se responde a la solicitud sobre la misma en los controles. El mensaje y el sentido del mismo vienen a ser en una gran mayoría de los casos menos importantes que las formas previamente acordadas del decir.

La clave para dar con una buena redacción, en este contexto, es acertar con las expectativas del profesor. Puesto que la mayoría de alumnos son a este respecto autodidactas formados en la ritualización de la cultura escolar cada alumno trata de adivinar las intenciones y los criterios de evaluación que los profesores ponen en juego para dar en el blanco de lo que de ellos se espera en las tareas puestas. Hay quien pide respuestas breves y concisas, hay quien quiere repetición de consignas dadas y quien premia la riqueza de ideas, y quien la coherencia del discurso, y quien la divergencia en el discurrir, y quien la ortografía, y quien la caligrafía o la presentación... Dar en el blanco de las expectativas viene a convertirse en el ser de la expresión escrita también, que es sentida y vivida como objeto de evaluación y como tal, portadora de mensajes no explícitos pero sí suficientemente pautados como para dar respuestas conformadas.

Estoy aludiendo en este punto a la dimensión formal, de consumo escolar exclusivo interno, en la cual la escuela, pienso, ha centrado en exceso su atención en detrimento de la dimensión funcional y creativa, esencialmente ligada a la formación y desarrollo del pensamiento autónomo y crítico del alumno, porque se ajusta con más facilidad a los cánones establecidos en el desarrollo del proceso instructivo.

No es de extrañar en esta visión panorámica que la enseñanza de la Lengua haya girado en torno a los núcleos conceptuales más formales - los estudios lingüísticos actuales acentúan con sus métodos de investigación empírica estos aspectos, descartando el estudio del significado y las implica- 
ciones sociales de la lengua (Beaugrande, 1987)- porque también son los que más se ajustan a las formalidades del sistema escolar, regido durante bastante tiempo por concepciones que acentúan la aplicación de soluciones técnicas descontextualizadas (racionalidad técnica), dejando de lado las aplicaciones prácticas del conocimiento en el desarrollo del curriculum.

Me refiero, en el caso de la enseñanza de la Lengua, al excesivo protagonismo que históricamente ha tenido, y creo que sigue teniendo, la enseñanza de la Gramática en los programas escolares, sustrayendo la atención de las partes más sustantivas y dinámicas de la Lengua, sobre todo si se tiene en cuenta el período de formación y crecimiento intelectual, biológico, social y moral de los alumnos. $E$ incluso, estableciendo una jerarquía entre las múltiples facetas que componen el área de Lengua como unidad globalizadora, de la que han salido perjudicadas las dimensiones que afectan al desarrollo del alumno como entidad social e intelectualmente desarrollada. «No hay que maravillarse por tanto, como advierte G. Rodari, si la imaginación, en nuestras escuelas, es aún tratada como la pariente pobre en comparación con la atención y la memoria; escuchar y recordar escrupulosamente constituyen aún las características del escolar modelo, que es además el mas cómodo y maleable» (Rodari, 1979, pág. 189). Pero también ha ido en detrimento de la exploración y de la comprensión y del control del propio mundo del sujeto que aprende, limitando las relaciones con otros y dificultando el desarrollo y exploración de la sensibilidad estética y moral.

Son muchas las razones que justifican la pervivencia y supremacía de la enseñanza de la Gramática y de los análisis morfosintácticos sobre otros componentes del sistema lingüístico, aunque cada vez se pone más en cuestión el orden de prioridades en el área de Lengua y se buscan y ensayan alternativas innovadoras. Movimientos de renovación pedagógica, nuevos enfoques curriculares preocupados por las aplicaciones prácticas del conocimiento y centrados en el desarrollo profesional del docente y en la participación del sujeto en los procesos de aprendizaje, irrupción de los estudios sociolingüísticos, aportaciones importantes de la psicología cognitiva en la adquisición y desarrollo del lenguaje, son corrientes de pensamiento que llevan a cuestionar la enseñanza tradicionalmente centrada en la Gramática. De todos modos, como decía, está muy arraigada en la tradición escolar, favorecida por un sistema de enseñanza orientado a la transmisión y al control más que a la creación y desarrollo de pensamiento y de cultura. La enseñanza de la Lengua, como de otras disciplinas, fomenta aquellas partes no problemáticas sobre las que es fácil ejercer el control y, en el reparto de oportunidades selectivas, asegurar la distribución "científicamente» planificada.

Por otra parte, los sistemas de formación del profesorado, centrados en currículos multidisciplinares, pero no integradores, no hacen más que reproducir en sus esquemas la tradición escolar que se pretende superar. De hecho, siendo importante la Lingüística en la formación intelectual del docente, ha desplazado el valor práctico de la formación para la enseñanza en nombre de una formación conceptualista y extremadamente verbalizadora para la comprensión de la(s) teoría(s) lingüísticas más recientes.

En esta encrucijada, el profesor que sale de la Universidad o de las Escuelas de Formación del Profesorado carga con un bagaje considerable de conocimientos teóricos que muy poco, si algo, tienen que ver con las ne- 
cesidades educativas que va a encontrar en el medio escolar en el que desempeñará su quehacer didáctico, a no ser que se trastruequen los objetivos haciendo de la enseñanza escolar un curso de iniciación a la especialización. Como señala con buen tino Alarcos Llorach (1980), «la proliferación de enfoques diferentes en estos estudios ha desembocado en un revoltijo de terminologías concurrentes que no hacen más que oscurecer y confundir el panorama del objeto de nuestra actividad. Los especialistas pueden, con ligero esfuerzo, sobrenadar esta marea teórica, pero las gentes normales interesadas en entender cómo funciona ese instrumento de la lengua que utilizan y las víctimas discentes e inocentes de las disciplinas lingüísticas quedan mareadas ante el caos que se desploma sobre ellos".

Todo lo cual nos hace pensar que se ha producido una notable desviación de los objetivos principales de la enseñanza de la Lengua (comprensión y expresión oral y escrita, sustancialmente), en la que algunas partes se han visto relegadas, llegando incluso a establecer parcelas aisladas en el área de Lengua que cuentan con sus propios especialistas «incomunicados» y que disfrutan de diferente status de conocimiento y de reconocimiento social. Quien investiga/sabe de Lectura desconoce o no tiene la obligación de saber de Escritura o de Gramática o de Literatura o de Lingüística; y cada comunidad - $; 0$ ghetto? - de especialistas celebra sus propios congresos, reuniones o simposios. En esta atomización del conocimiento y reparto de la Unidad Lengua las partes que tienen que ver con los asuntos prácticos y de enseñanza son las menos beneficiadas y en principio las que gozan de menor prestigio. Piénsese en las cuestiones relacionadas con la Lectura y la Escritura, pero también la Ortografía y la corrección idiomática, que a duras penas encuentran un lugar de estudio y de investigación propio en la Universidad.

Dentro de estos conocimientos, normalmente identificados como instrumentales - lo que de por sí ya define status por oposición a conceptuales- podemos comprobar cómo el proceso de escolarización ha favorecido siempre aquellas actitudes que comportan conductas y respuestas receptivas frente a aquellas que exigen de los sujetos posturas participantes, críticas, responsables, interactuantes, creativas. De este modo, la actividad de leer es a la de escribir como la actividad de escuchar lo es a la de hablar. Pero en ambas equivalencias el concepto de actividad está mediatizado por el mismo proceso de escolarización.

El siguiente esquema, elemental por demás, trata de reflejar esta situación que en gran medida representaría los cauces y ejes de transmisión de la información habituales en la enseñanza, independientemente de las disciplinas particulares:

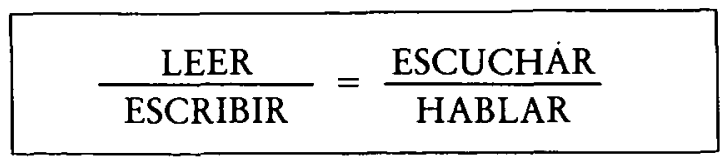

Sobre esta elemental relación podemos comprender que el proceso de escolarización se asienta sobre pilares tan básicos, donde las actividades receptivas sobresalen, en dedicación y en atención, sobre las actividades que tienen como resultado la elaboración y la creación de algo. La instrucción favorece y refuerza las babilidades de recepción, es decir, leer y oir, sobre 
las habilidades de producción, que son escribir y hablar, en cuanto comprensión y expresión propias del pensamiento. Como consecuencia, se premian los ejercicios de memoria, de recitado y de repetición así como la convergencia/homologación de pensamiento en cuanto a la adquisición de los contenidos, la sumisión y la pasividad en cuanto a la conducta frente al desarrollo del pensamiento crítico y divergente y a la comprensión y a la interacción en cuanto al conocimiento. Se anteponen, en suma, las consideraciones académicas del conocimiento, en el cual no sucede nada nuevo porque todo está previamente seleccionado, ordenado, simplificado, objetivado, descontextualizado, programado minuciosamente según lo requieren las concepciones tecnológicas, en fin, a la consideración social del conocimiento, de naturaleza esencialmente conflictiva, histórica, problemática, inacabada, dialéctica.

No es de extrañar que en esta relación sean los profesores quienes hablen (que no tanto escriben) y los alumnos quienes escuchen pasiva y pacientemente. En la clase de Lengua el silencio del alumno viene siendo una constante que refleja los desajustes que se producen entre una enseñanza que se proclama y necesita ser abierta, participativa, integradora, cooperativa y grupal y un aprendizaje, por contraste, que resulta pasivo, desinteresado, competitivo, inhibidor, callado, individual e individualista.

\section{DE LA ENSEÑANZA DE LA REDACCION DESDE LA PERSPECTIVA DIDACTICA}

\section{De la perspectiva didáctica}

Valga como advertencia introductoria en esta parte y a la vez como puente con lo que sigue que lo dicho hasta aquí está justificado desde una interpretación didáctica de la enseñanza de la Lengua, cuyo soporte epistemológico y pragmático descansa en concepciones curriculares que entienden la enseñanza como actividad social históricamente construida. Igualmente se reconoce condicionada por las coordenadas espacio-temporales en las que se desenvuelve y, como tal, actividad crítica de investigación y de innovación constantes. En esta práctica social que es la enseñanza se atiende en esta perspectiva al desarrollo profesional del docente al darle el margen de autonomía que su preparación requiere para crear y ensayar sus propias ideas y proyectos curriculares. Esto sea entendido, insisto, como respuesta coherente a la preparación profesional que constituye su formación universitaria especializada en un área concreta.

En este sentido, marca diferencias muy claras con concepciones tecnológicas del curriculum, normalmente derivadas de la psicología conductista, las cuales dejan estas cuestiones en manos de entendidos y de experimentados expertos con frecuencia alejados de los avatares cotidianos del aula. El control de todo el proceso viene a ser, en esta última interpretación, una de las preocupaciones primordiales porque sobre él, además de las necesidades estrictamente académicas, recae el peso de las decisiones burocrático-administrativas. Por ello exigen que el conocimiento se transforme en resultados inequívocos, medibles con precisión e incluso predecibles (muchas de las experiencias de los CAP responden a estos planteamientos). 
Si este modo de concebir el curriculum responde a una racionalidad técnica, la primera a la que aludía y que sirve de marco de referencias para explicar el enfoque que doy a mis palabras apunta, por contraste, a una racionalidad práctica que tiene en el aula su propio banco de pruebas y de validación, de investigación y de desarrollo del conocimiento. Lejos de ser algo ya dado y concluyente, el conocimiento y el contenido para aprender se entienden como problema y cuestión pendiente de solución. Se trabaja más sobre hipótesis que la propia práctica irá investigando, contrastando y resolviendo que sobre resultados predecibles recogidos en programaciones definitivas, normalmente hechas por personas ajenas a lo que se hace en el aula. En el caso de la enseñanza de la Redacción este enfoque brinda la oportunidad para que el profesor ensaye en el aula fórmulas y maneras que permitan desarrollar la Lengua Española en múltiples direcciones. Pero también queda en su responsabilidad asegurar la calidad de lo que el alumno aprende.

Entendidos de este modo la enseñanza y el aprendizaje, en el desarrollo del curriculum todo se discute, todo se pone en cuestión, todo necesita ser investigado de nuevo. Bien sea el contenido, bien los métodos, bien las relaciones que se establecen en el aula, bien las funciones del profesor y las funciones del alumno, bien el proceso de escolarización, bien las formas de evaluación. La dimensión práctica y el desempeño ético de la profesión, ejercida dentro de un amplio margen de responsabilidad y de autonomía -que no de aislamiento o de insolidaridad con el resto de la comunidad educativa - serían puntos de apoyo sustanciales y fuertes en los que esta concepción se sostiene. Si desde el punto de vista tecnológico se busca la convergencia del pensamiento por medio de pruebas objetivas que miden minuciosamente los resultados de aprendizaje a costa de la hipersimplificación de los procesos de pensamiento y de los conocimientos que el alumno debe asimilar, en la concepción en la que enmarco mis propias explicaciones el aprendizaje y la propia evaluación forman parte del proceso de investigación, que es aprendizaje a través del cual el conocimiento se bace, descubriendo los propios caminos recorridos para acceder a él.

Esto trae ventajas no exentas de dificultades. Entre las primeras cabe señalar, a modo indicativo, las siguientes:

- Se toma conciencia y se demuestra en el hacer que el conocimiento es problemático, no simplificación de manual escolar.

- Que es dinámico, fruto de intereses históricos, sociales, ideológicos, culturales en muchos casos, que no es neutro.

- Que se accede a él con trabajo, pero que contarlo escucharlo/recordarlo no es poseerlo.

- Que es algo que está al alcance de la mano, no en posesión de los expertos.

- Que tiene implicaciones sociales y axiológicas múltiples.

- Que todo conocimiento adquirido tiene carácter de provisionalidad, sometido a una revisión constante del conocimiento.

Entre las dificultades:

- Que la historia curricular y el contexto escolar y social no van en esta dirección. 
- Que la resistencia de alumnos, de padres, de compañeros, de la sociedad, son fuertes.

- Que falta infraestructura administrativa y de formación docente.

- Que exige del profesor una formación continuada en su área de conocimiento pero también en la didáctica aplicada a su área de conocimiento.

\section{De la enseñanza de la Redacción}

Si a la enseñanza de la escritura se le dedica poca atención a lo largo de los años de escolaridad - sólo la adquisición de las destrezas elementales tienen atención programada y pormenorizada-, el aprendizaje de la Redacción pasa prácticamente desapercibida en el curriculum. Siendo reconocidas su importancia y la gran laguna deficitaria en la formación de los alumnos no cuenta con una tradición didáctica propia, cuando por sus alcances y su complejidad, pero también porque es necesario recuperarla como parte del mismo aprendizaje, estaría suficientemente justificada.

Entre las razones que se pueden aducir para este desajuste cuenta el hecho de que la Redacción no figura en un capítulo específico y aparte dentro del «cajón de-sastre» que es la Lengua. Pero además, las formas de enseñanza tampoco favorecen un seguimiento directo que permitan detectar las formas externas de apercibimiento y de observación del hecho de escribir distinguiendo en ellas la calidad de lo que con ellas se dice ni el proceso creador e imaginativo que antecede al resultado que normalmente es sometido a valoración. Sorprende en la literatura especializada cuánto se habla de destrezas y de habilidades y cuán poco de imaginación, creatividad, libertad de expresión, espontaneidad, necesidad de decir algo, intereses del alumno. Entre otras razones, porque, por una parte, las investigaciones sobre la Lengua se han ido desentendiendo sistemáticamente del estudio del significado; y por otra, porque las técnicas didácticas han acentuado el control sobre las partes más dadas a tal empeño, en menoscabo de la comprensión y de la asimilación de los contenidos a que tales ejercicios supuestamente debían llevar.

En ambos casos, lingüístico por un lado y didáctico por otro, el contexto intelectual y el proceder metodológico estaban marcados por el empirismo-experimentalismo reinante, lo cual condicionó el desarrollo de fórmulas alternativas centradas en los procesos cognitivos y en las implicaciones sociales e intersubjetivas tanto de la lengua como de las tendencias curriculares. Si el Estructuralismo marcó las pautas que definían el entender y el hacer científico de la Lengua, la Psicologia Conductista, coincidente en sus postulados con aquél (Alvarez Méndez, 1983), vino a ser en la Educación el marco de referencia obligado para determinar los procedimientos didácticos más eficaces de intervención en el aula. Fruto de esta coyuntura, la enseñanza de la Lengua se volvió, como en otras disciplinas, en un objeto neutro de conocimiento desligado de cualquier dimensión histórica y social y fue tratada como materia de programación técnica y objeto de evaluación objetivada, aunque ello fuera en aras de las dimensiones más dinámicas de la misma, entre ellas la creación, la comunicación y la comprensión, que no se ajustaban a las exigencias del entender positivista/conductista. El curriculum centrado en objetivos operativos que identifican el aprendizaje con las conductas manifiestas en que resultó la concreción de 
las concepciones conductistas de la educación creó barreras para el aprendizaje dada la práctica habitual de pruebas objetivas adoptadas por muchos profesores al sacrificar la elaboración y el desarrollo del pensamiento en favor de una pretendida objetividad a la hora de calificar que recogen las preguntas cerradas que exigen respuestas cortas y ya estructuradas, con el agravante de que tales fórmulas de evaluar redujeron considerablemente las pruebas de desarrollo y de ensayo atraídos los profesores "por la facilidad seductora de los tests de puntuación múltiple» (Monaghan, 1987). Se cierra así la posibilidad de que los alumnos exploren ideas sugiriendo o ensayando sus propias soluciones.

Se llega así a la situación paradójica, ya antes aludida, de que el alumno escribe mucho durante el período escolar, pero comunica muy poco. Y menos aún, expresa, manifiesta pensamiento propio, sentimientos o actitudes y valoraciones personales. La Redacción se vuelve en ejercicio rutinario, mecánico y ajeno, que es necesario superar, pero que en muy pocas ocasiones tiene la intención real de decir algo porque no es sentida ni vivida como necesidad personal de comunicar. A fin de cuentas, en el contexto escolar viene a ser una tarea académica más, con la que hay que cumplir, forzada normalmente por intereses que no son los propios.

La situación creada, desde tales concepciones epistemológicas y desde el proceder didáctico que siguió a tales enfoques derivó en una pérdida de orientación en los objetivos básicos de la enseñanza de la Lengua, y en particular, de la Redacción.

Como medida primaria para reconducir el quehacer didáctico necesitamos encauzar y recuperar los objetivos teniendo en cuenta que no interesa tanto transmitir información metalingüística o desarrollar destrezas o fórmulas encantadas que desencadenen procesos creativos sino desarrollar una gran capacidad de actividad intelectual alrededor de unos pocos conocimientos representativos y significativos de cara a la formación integral del alumno.

Como sentimiento y como ambición formativa necesitamos asimismo asegurar en la enseñanza de la Lengua la comprensión y la expresión oral y escrita cualificadas que permitan la comunicación, en el aula y fuera de ella, potenciando a la vez que los alumnos puedan acceder y participar de los bienes culturales, cientificos y tecnológicos comunes. Pero no sólo como consumidores pasivos de lo que otros hacen sino para disfrutarlos y para crearlos. Con este ánimo y por esta vía podremos llegar a hacer del alumno aquella persona creativa que siempre soñamos ser, capaces, como señala G. Rodari, de romper continuamente los esquemas de la experiencia. Porque creatividad es sinónimo de pensamiento divergente. «Es "creativa", en sus palabras, una mente que trabaja siempre, siempre dispuesta a hacer preguntas, a descubrir problemas donde los demás encuentran respuestas satisfactorias, que se encuentra a sus anchas en las situaciones fluidas donde otros sólo husmean peligro; capaz de juicios autónomos e independientes (incluso del padre, del profesor y de la sociedad), que rechaza lo codificado, que maneja objetos y conceptos sin dejarse inhibir por los conformistas. Todas estas cualidades se manifiestan en el proceso creativo. Y este proceso tiene un carácter festivo: siempre, aunque se trate de "severas matemáticas". Y en esto, en palabras de Marta Fattori que recoge el mismo Rodari, 'todos podemos ser 'creativos' a condición de no vivir en una socie- 
dad represiva, en una familia represiva, en una escuela represiva"" (Rodari, 1979). Es el caldo de cultivo apropiado para hacer de la educación un quehacer creativo al que merece la pena dedicar tiempo y esfuerzos, aunque a veces las dificultades parecen obligarnos a caminar a contracorriente.

El poder de las teorías que generan los currículos es definitivo en el desarrollo de los mismos. Sucede a veces, no obstante, que aquéllas se pierden o se ocultan con un discurso encubridor en la práctica docente, cuando ésta queda definida y marcada por aquéllas. La enseñanza de la escritura y de la lectura evidentemente implican teorías. De ellas se derivan las concepciones sobre lo que es el aprendizaje escrito y lector, sobre lo que es aprender y la forma de hacerlo, sobre lo que aprenden los alumnos y la forma de mostrar que ya se ha aprendido y tamibén sobre la naturaleza del alumno.

En las páginas precedentes ya aludí al llamado enfoque «científico», entendido restrictivamente en una dimensión empírico-experimentalista. Los estudios cuantitativos se consideran en esta perspectiva como única vía de hacer ciencia y de acceder al conocimiento: el aprendizaje se interpreta desde la descripción conductual del saber, siendo la medida objetiva, es decir, expresamente manifestada en determinados comportamientos observables, la única forma válida para comprobar las adquisiciones del alumno. El auge que adquirieron las pruebas objetivas, aún vigente, responde a estos postulados.

Recientemente van cobrando fuerza, y en algunas partes, consolidándose, otras formas de concebir el curriculum y su desarrollo, que tienen como fuente de inspiración, no los modelos de las ciencias sicométricas, sino la Antropología, la Etnografía, la Sociología y la Filosofía (Stenhouse, 1981 y 1985; Carr y Kemmis, 1983; Kemmis y McTaggart, 1987; Gimeno Sacristán, 1988).

Desde este enfoque, las seguridades establecidas hasta entonces se quiebran. Enseñanza y aprendizaje se entienden como cara y cruz de un mismo proceso de investigación. Se aboga por el desempeño ético, antes que técnico, de la enseñanza y se reivindican la autonomía y la responsabilidad que permita a los profesores comprometerse con su trabajo. Para lo cual necesitan a su vez la libertad de decisiones que normalmente les sustrae el Poder, sea político, eocnómico, social o administrativo, e incluso, diría, la propia formación que reciben.

Hago, como última referencia, alusión a la evaluación del rendimiento de los alumnos, concretamente en el caso de la Redacción. Y parto de la siguiente consideración: ni la Comunicación ni la Expresión ni la Literatura están hechas para ser valoradas sobre índices académicos, que al fin y al cabo son simples convenciones para la acreditación acdémica. Sólo el sistema instructivo ha convertido ficticiamente cada disciplina que ha creado artificialmente como materia de estudio en objeto y objetivo de evaluación/calificación. Y hay ocasiones, como las dos aludidas, por restringir en este punto mi reflexión, en las que el intento de hacer coincidir las expectativas y las conveniencias en juego por cada parte, que son muchas, vuelve el "asunto educativo" en una encrucijada de intereses y de valores que entran en abierta contradicción.

Lo que en principio puede entenderse como necesidad sentida y compartida de conocer los procesos que se están llevando a cabo en el aula, del 
profesor como responsable de la calidad de lo que los alumnos aprenden, de la forma en la que aprenden los alumnos como responsabilidad de ellos mismos, de la interacción entre ambos y de los alumnos entre sí y con el profesor, ha venido a ser simple y llanamente ejercicio de control selectivo -del profesor y del alumno-, por más que el discurso institucional insista en los aspectos formativos que ella comporta. Es fácil encontrarse en esta perspectiva con exámenes y controles establecidos que impiden realmente los procesos de formación que el profesor concienciado y comprometido quiera llevar a cabo en el aula.

Esto se evidencia en el caso concreto del aprendizaje de la Lengua, con pruebas y controles que fomentan un nivel de conocimiento y desarrollo idiomático válido para el consumo escolar y para la administración de los asuntos académicos, pero inhibidor de los recursos expresivos y comprensivos que puedan comprometer el expediente. Además, cuando el profesor corrige un texto y lo califica está dando a entender directamente y al mismo tiempo, cómo se debe leer y cómo se debe escribir según su propia interpretación, que se da por válida, la cual se convierte implícitamente en modelo de cómo escribir. Cuando el alumno escribe para la escuela conoce de antemano esta situación: aparte de sus propias experiencias, la intercomunicación e intercambio de experiencias entre los mismos alumnos permiten establecer los códigos de entendimiento que desvelan las expectativas y las formas de corregir de cada profesor. En consecuencia, el alumno escribe para el profesor, que es el destinatario real, a la vez que intérprete, él es el que decide entre lo literario y lo ordinario, y quien a la postre decide el valor académico de lo escrito, es decir, quien evalúa. En esta dinámica los alumnos tienden a adivinar $\mathrm{o}$ a interpretar lo que pide el profesor y cómo lo pide. El profesor, a su vez, suele dejar suficientes pistas para que el alumno pueda ajustarse a sus expectativas en las explicaciones de la clase. A través de ellas se dejan establecidas las pautas para el acuerdo. Todo forma parte de la ritualización socializadora que se da en el proceso de escolarización.

3.2.5. Como sugerencias y aliento para quienes tienen ganas de comprometerse con formas alternativas de enseñar propongo, a modo de conclusión, las siguientes consideraciones:

* Antes de poner una tarea de Redacción a los alumnos, pregúntese si realmente merece la pena dedicarse a tal empeño en las condiciones en las que se da. Antes de pedirles a los alumnos que escriban, indague si tienen algo propio que decir y si realmente tienen interés en decirlo. Animándolos y entusiasmándolos con el trabajo, que no forzándolos aunque lo hagan, logrará que ellos mismos se comprometan con su propio aprendizaje. Porque la Redacción debe ser vista como una actividad de liberación, no como un castigo. Y para comprender las dificultades a las que se someten los alumnos haga usted mismo el ejercicio.

* Si lo que realmente interesa es que los alumnos escriban, que escriban. Pero sin que sobre su resultado recaiga el peso de una calificación. El aprendizaje de un contenido curricular es un proceso que no se sabe bien cuándo termina. La calificación suele dar por zanjados procesos abiertos. El conocimiento de que el profesor es siempre el destinatario final que juzgará las redacciones y la sospecha o el conocimiento de que los criterios por los cuales un trabajo creativo, imaginativo, dinámico, eminentemente 
subjetivo, manifestación de pensamiento crítico y constructivo, aprendizaje en si, no están claros, convierte todo el proceso en un ejercicio de representación, que cuenta con sus propios cauces de reconocimiento académico establecidos. Pero sucede que lo que desde el punto de vista de la corrección es rentable no lo es en el mismo grado y sentido en el de la producción.

- Cuente con los alumnos y con los recursos idiomáticos con los que llegan al aula. Las diferencias sociales y culturales inciden directamente en las formas habituales de expresión. Rechazarlas o dejarlas de lado sólo lleva a que el alumno utilice dos niveles de Lengua distintos, uno para la escuela, y otro, el que más aprecia y siente más próximo, para entenderse fuera del aula, aunque sea en el patio de la escuela (Alvarez Méndez, 1987). Pero también cuente con ellos para trabajar e investigar juntos, el profesor con los alumnos, los alumnos entre sí. Aunque en algunas situaciones la disposición de libros de texto pueda ayudar al aprendizaje cada día van aumentando los recursos didácticos que no "atan" a un manual: periódicos, medios de comunicación social, talleres de escritura, dramatización, elaboración de diarios en la clase, etc.

- Es necesario invertir el tiempo y la importancia que se le concede a la evaluación, así como crear fórmulas nuevas de evaluar que estimulen el pensamiento y la imaginación. Como responsables de la enseñanza nuestra tarea debe centrarse en perfeccionar nuestra propia práctica. El aula es el lugar dióneo en el que el profesor puede liberarse de las presiones a las que como agente social está sometido. Sin renunciar a la autonomía y a la responsabilidad que representa el ejercicio de la profesión, la dimensión ética es la garantía del compromiso honesto del trabajo del profesor. Lo que se pretende es que el alumno aprenda a escribir primero, para luego escribir para aprender y para comunicarse - no se pueden poner barreras artificiales al aprendizaje de la Lengua-, no tanto escribir para demostrar que sabe, que es tanto como escribir para ser evaluado. Ganaríamos en satisfacción y recualificación de nuestro trabajo si tanto esfuerzo y tiempo gastados en controlar lo dedicáramos a asegurar un aprendizaje de calidad. Con la ventaja de que nuestra área de intervención, que es la Lengua, está presente en todas las áreas curriculares y es el vehículo imprescindible para nuevos y distintos aprendizajes. Desligar la enseñanza de la Redacción del resto de los aprendizajes contribuye a hacer del mismo hecho de escribir una actividad que no tiene más significado y alcances que el cumplimiento con las exigencias académicas.

- La Lengua Escrita es un producto cultural de la Historia cuya enseñanza y aprendizaje no se pueden desentender de la Cultura y de la Sociedad en que se da. Como actividad humana conlleva determinantes y consecuencias sociales que hay que tener presentes. Porque así como es medio de liberación puede ser igualmente utilizada como medio de opresión o de engaño. Desde la perspectiva didáctica que ha presidido toda mi exposición la opción en este sentido es clara, aunque no sea ni la más fácil ni la más cómoda: si no libera, la lengua somete. La educación debe apostar por la liberación que da el acceso al saber.

- No centre ni oriente la enseñanza de la Redacción hacia el examen. Hacerlo pervierte todo el esfuerzo serio encaminado a la formación del pensamiento y a la asimilación de los conocimientos que abren el paso para acceder a los bienes culturales, científicos y tecnológicos de la sociedad. Es 
además desperdigar las energías que deben estar centradas en el aprender. Dirija todos sus esfuerzos a que los alumnos comprendan lo que van haciendo, al tiempo que hacen suyos los contenidos una vez que usted se haya asegurado de que merece la pena dedicarse a ello. Los alumnos tienen que tomar conciencia de que el aprendizaje es responsabilidad de ellos. Coaccionarlos o amenazarlos con un control sólo sirve para cubrir el expediente. De otro modo, siempre estarán pendientes de lo que usted $\mathbf{u}$ otro les dé, en actitud receptiva, probablemente con resistencias no manifiestas, dispuestos a memorizar o a repetir cuándo y cuánto se les demande.

- Deje que los alumnos descubran el placer y la satisfacción de aprender por ellos mismos, sin la amenaza permanente del control. La creación y la libertad de expresión no conocen de lindes. Son manifestaciones de la propia personalidad de quien se expresa en ellas y no fuente de información para juzgar.

- Deje que escriban, en cantidad. La calidad es un estadio posterior, fruto en parte del ejercicio y del trabajo, y sobre todo del interés que despierte en el alumno esta actividad, comprometiendo su deseo natural de expresarse y de establecer nexos entre su formación intelectual y su vida, dando sentido a lo que está aprendiendo. Para ello es necesario que las tareas que tengan que realizar enganchen con su vida y las contextualice, desarrollando el pensamiento crítico y creativo como fuente de inspiración de la Redacción.

- Cuando corrija un escrito, que sus anotaciones sean siempre de orientación y de ayuda y de estímulo, nunca motivo de que los alumnos acudan a las trampas del lenguaje para decir sin comunicar nada, en la búsqueda de la recompensa a su esfuerzo que es la nota, aunque en el premio no vaya el aprendizaje.

- Antes de enseñar es necesario crear las condiciones adecuadas para el aprendizaje: la amenaza siempre pendiente de ser calificado es un estorbo, nunca una ayuda. Aunque en el discurso pedagógico se haya hablado de evaluación formativa y de evaluación sumativa. Quédese con la primera. Porque aquellas prácticas de evaluación que no eduquen no pueden formar y deben descartarse. Si el alumno y usted mismo no aprenden de las prácticas de evaluación, es señal inequívoca de que tales prácticas dejaron de ser formativas y de que sirven a otros intereses.

\section{Referencias}

Alarcos Llorach, E. (1980). "La práctica del análisis sintáctico*. En: Actas del 1.e Simposio para profesores de Lengua y Literatura Españolas. Madrid: Castalia.

ALVAREZ MÉNDEZ, J. M. (1983). Lingǘstica fundamental; introducción a los autores. Madrid: Akal.

- (1987). Didáctica, Curriculo y Evaluación. Barcelona: Alamex.

- (1987). Didáctica de la lengua: un enfoque desde la lingüistica. Madrid: Akal.

CARR, S. y Kemmis, S. (1988). Teoría critica de la enseñanza. Barcelona: Martínez Roca.

CASTRO, A. (1922). «La enseñanza del español en España». En: Alvarez Méndez, J. M. Teoria Lingüistica y enseñanza de la Lengua. Madrid: Akal, 1987.

BeAugrande, R. (1987). "Writing and Meaning: Contexts of Research». En: Matsuhashi, Anne (ed.). Writing in Real Tuglewoods, New Jersey.

DijK, T. Van (1979). La ciencia del texto. Barcelona, Paidós.

ELlIOT, J. (1989). La investigación-acción en educación. Madrid, Morata.

GoODSON, I. (1983). School Subjects and Curriculum Change. Londres: Croom Helm. 
Kemmis, S. y McTAGgaRT, R. (1988). Cómo planificar la investigación-acción. Barcelona: Laertes.

LENZ, R. (1912). «¿Para qué estudiamos gramática?». En: Alvarez Méndez, J. M. Teoria lingüistica y enseñanza de la Lengua. Madrid: Akal, 1987.

Monaghan E. J. y Saul, E. W. (1987). «The Reader, The Scribe, the Thinker: A Critical Look at the History of American Reading and Writing instruction». C. Popkewitz, Th. (ed.). The formation of School Subjects: the Struggle for Creating an American Institution. Nueva York, The Falmer Press.

POPKEWITZ, T. (ed.) (1987). The Formation of School Subjects: the Struggle for Creating an American Institution. Nueva York, The Falmer Press.

PERRENOUD, Ph. (1990). La construcción de éxito y del fracaso escolar. Madrid, Morata.

Queneau, R. (1989). Ejercicios de estilo. Madrid, Cátedra.

ROCKWELL, E. (1982). «Los usos escolares de la lengua escrita». En: Ferreiro, E. y Margarita Gómez Palacio (eds.). Nuevas perspectivas sobre los procesos de la lectura y escritura. México, Siglo XXI.

RODARI, G. (1979). Gramática de la fantasía. Barcelona, Avance.

STENHOUSE, S. (1984). Investigación y desarrollo del curriculum. Madrid, Morata.

- (1987). La investigación como base de la enseñanza. Madrid, Morata.

VYGOTSKI, L. S. La imitación y el arte en la infancia. Madrid, Akal, 1982.

WhITE, Edward M. Developing Successful College Writing Programs. Francisco: Jossey-Bass Publisher, 1989. 


\section{La enseñanza de la redacción desde el punto de vista didáctico. J. M. Alvarez. CLE 1 1991, 10, 11-30.}

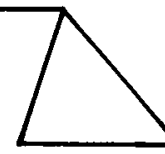

\section{Resumen}

Este trabajo se centra en la importancia de la redacción como medio de aprendizaje, siendo al mismo tiempo aprendizaje en él se analizan algunos aspectos en el proceso de escolarización que dificultan el desarrollo del aprendizaje de la redacción centrado en la comprensión y en la expresión del pensamiento del propio sujeto. Para superarlos es necesario partir del convencimiento de que la expresión escrita es medio activo de pensamiento y de aprendizaje a través del cual el sujeto puede desarrollar sus propias capacidades y lograr la autonomía intelectual que le permitan acceder a las fuentes de los saberes histórica y socialmente establecidos y abrir caminos bacia otros nuevos.

Datos sobre el autor: Juan Manuel Alvarez Méndez es Profesor Titular de Didáctica y Organización Escolar de la Universidad Complutense. Por formación y por dedicación ha centrado su interés en la Didáctica de la Lengua Materna y en la Didáctica General, areas en las que cuenta con diversas publicaciones.

Dirección: Universidad Complutense de Madrid. Facultad de Educación. Departamento de Didáctica y Organización Escolar. Edificio de la Almudena. Ciudad Universitaria, 28040 Madrid.

(C) De todos los artículos. Deberá solicitarse por escrito autorización de CLE para el uso en forma de facsímil, fotocopia o cualquier otro medio de reproducción. CLE se reserva el derecho de interponer las acciones legales necesarias en aquellos casos en que se contravenga la ley de derechos de autor.

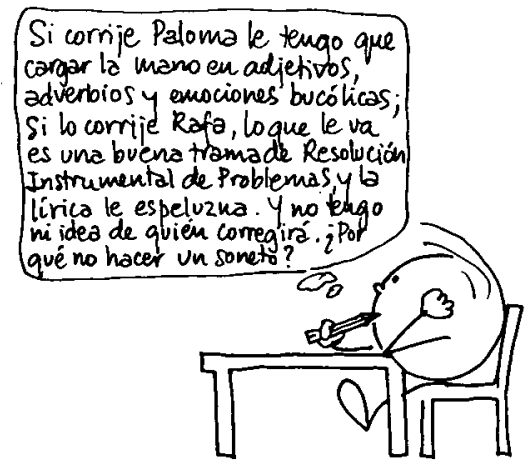

